Sri Lanka Journal of Bio-Medical Informatics 2010;1(2):120

DOI: $10.4038 /$ sljbmi.v1i2.1773

\title{
eHEALTH SRI LANKA 2010
}

Health Informatics Society of Sri Lanka is pleased to call for papers for the eHealth 2010 SRI LANKA Conference scheduled for the 16 and 17 September 2010 Abstract closing date: 30 June 2010

\section{(Please note the new dates of the conference)}

Please visit http://hissl.org/ for more details. $* * * * * * * * * * * * * * * * * * * * *$

\section{e-Health Sri Lanka 2010 is the Official Conference of the Health Informatics Society of Sri Lanka (HISSL)}

Since the late nineties, HISSL Scientific Congresses have grown to become the main biomedical informatics conference in the country. These conferences are organized to give the opportunity to those in the health care sector to update their knowledge and contribute to the rapidly evolving knowledge in the field of biomedical informatics. An interesting programme is planned including plenary lectures, symposia, workshops and oral as well as poster presentations.

eHealth 2010 would be an ideal forum to share information and results of research generated by investigators in medicine, science and the electronic communication technology industry working in the field of biomedical informatics. 